\title{
Theoretical justification and development of technical means to ensure environmental safety of urban water management systems
}

\author{
Elguja Khetsuriani ${ }^{1,2}{ }^{*}$, Vladimir Bondarenko ${ }^{3}$, Teona Khetsuriani ${ }^{1}$, and Timur Khetsuriani ${ }^{2,4}$ \\ ${ }^{1}$ M. I. Platov South Russian State Polytechnic University (NPI), 346400 Novocherkassk, \\ Russia \\ ${ }^{2}$ Don State Technical University, 344000 Rostov-on-Don, Russia \\ ${ }^{3}$ Novocherkassk Engineering and Land Reclamation Institute named after A.K. Kortunov \\ FSBEI HE Don State Agrarian University, 346428 Novocherkassk, Russia \\ ${ }^{4}$ Rostov State Medical University, 344022 Rostov-on-Don, Russia
}

\begin{abstract}
Ecological safety of water intakes in urban water management systems and the creation of comfortable living conditions for people can be ensured only with a comprehensive solution to the problems associated with improving water quality when it is taken from the source, preserving biodiversity in the water body, protecting against blue-green algae, zebra mussel and mechanical pollution. The water intake technological complex as a part of the natural-technical system (NTS) specialized type "Natural water environment - Urban water management complex - Urban water supply system" ("NWE - UWMC - UWSC"), as the main multifactorial technogenic component, includes various types of hydraulic structures and protective devices interconnection, interaction and relationship (IIR), which ensure the environmental safety (ES) of the urban economy. The studies have established that the functional IIR between the structural elements of the "UWMC" in the composition of this NTS type "NWE - UWMC - UWSC" determines the generalized design and technological solutions, which determine the complex of protective measures to ensure the ES preservation of health and the urban population life quality. Based on the results of complex (theoretical, laboratory, full-scale) studies, constructive and technological solutions have been developed to preserve the diversity of ichthyofauna (juvenile fish, etc.) in the water body, to ensure the protection of the water intake bucket from bottom and suspended sediments, sludge and floating objects coming from the water body, from toxic blue-green algae and fouling with zebra mussel of structural elements and technological equipment as part of the urban water management complex. Functional sequence of IIR structural and technological
\end{abstract}

\footnotetext{
* Corresponding author: goodga@mail.ru
} 
solutions (STS-1, STS-2, STS-3) between themselves (Fig. 1)

provides regulatory requirements for environmental safety.

\section{Introduction}

Human consumer attitude to nature has led to a disruption of the Earth's ecosystem natural balance, that is, to environmental pollution, a reduction in biodiversity and a shortage of drinking water. The global environmental problems of our time have created the inevitability of mankind's transition to reasonable control and regulation of anthropogenic impact on the natural environment. In particular, the cause of the current global problem of the high-quality drinking water lack lies not in natural processes, but in non-ecological water use. This problem can only be solved by careful use of water and a thrifty attitude to the planet water resources using environmentally friendly water supply systems.

The desire to improve the environmentally friendly protective, barrier and water purification effect of water intakes from surface sources, the waters of which contain mineral and organic pollution, necessitates the improvement of water intake and treatment facilities located directly in the watercourses and reservoirs channel and allowing at the same time water intake and preliminary water purification. The use of water resources in the household sphere of urban economies is carried out by sampling the estimated water consumption from the water body by the existing water intake facilities of urban water management systems [3]. So, in the lower reaches of the river Don from the Tsimlyansk reservoir to the mouth of the Azov city, according to the monitoring results, there are currently about 44 water intake complexes of water supply systems for municipalities, large settlements and economic facilities (Rostov NPS, Novocherkassk RHPP, Nesvetay TPP, etc.).

Based on the results of monitoring the functional work and environmental safety of the existing water intakes, a conceptual model of environmental safety assurance of water intakes as part of the urban water management system was developed (Fig. 1).

The article presents a theoretical substantiation of the development results of environmentally sustainable functioning of NTS specialized type "Natural water environment - Urban water management complex - Urban water supply system", which provides the IIR of constructive and technological solutions (STS-1, STS-2, STS-3), which ensure ecological safety of the urban water management system at the level of $90-95 \%$.

\section{Main part}

The formed ecological state as a factor of the ecological safety of urban water management complexes as part of NTS specialized type "Natural water environment - Urban water management complex - Urban water supply system" determines a complex of protective devices for water intakes to improve the existing and create the new constructive and technological solutions as part of the urban water management system, which in a systemic consideration determines the environmentally sustainable development of this type of economic activity, where the concept of "Development" means a necessary, directed, natural change in components of the environment. 
A systematic approach to the processes of interconnection, interaction and interrelation between protective constructive and technological devices (STS-1, STS2, STS-3) defined the methodology for studying water intakes as part of the urban water management system, as a technogenic component functioning on a water body, where quantitative and qualitative indicators of water resources are formed.

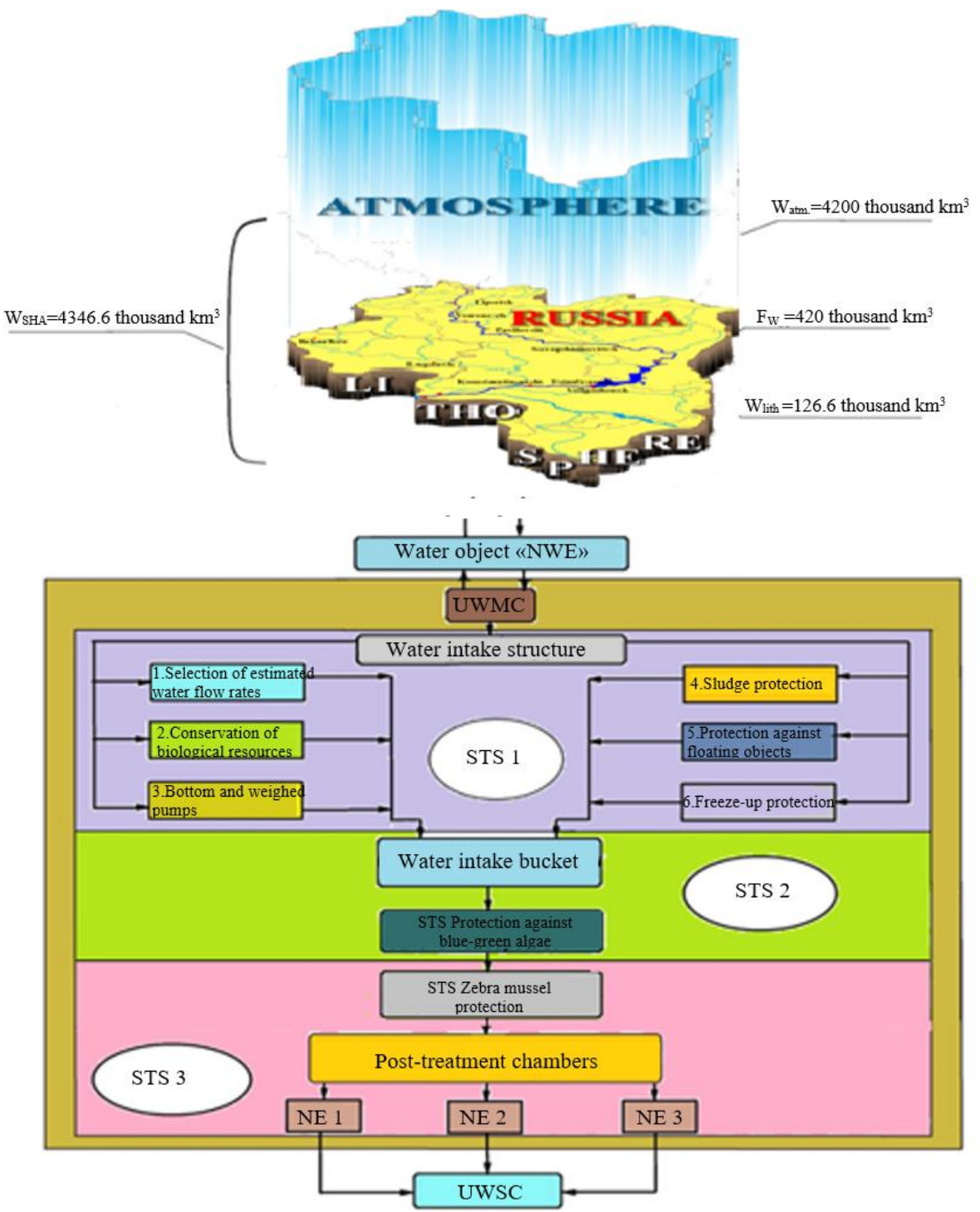

Fig.1. Specialized NTS type "Natural water environment - Urban water management complex - Urban water supply system"

Based on the results of the functional operation studies of the existing water intakes as part of a specialized type NTS «NWE-UWMC - UWSC» it was found that IIR with natural environments, in particular with the natural aquatic environment (the Don River), and with a water source, determines multipurpose functionality, on which 
level ES urban water management system for a number of important environmental indicators depends [5].

The most important environmental indicators are:

1. Indicator for the ichthyofauna diversity preservation in a water body, which determines the water intake bucket protection level in the urban water management system from the ingress (entry) of juvenile fish during the selection of estimated water flow rates $\left(\mathrm{Q} \mathrm{m}^{3} / \mathrm{s}\right)$ from the water source;

2. Indicator for the water intake bucket protection from the bottom inflow and suspended sediments coming from the water body, which, when accumulated, reduce the functional efficiency of the technological devices' structural elements as a part of the urban water management system;

3. Indicator of the water intake bucket protection from sludge and floating objects coming from a water body in different periods of the year;

4. Indicator of structural and technological elements' protection of the urban water management system from toxic blue-green algae, which negatively affect the quality indicators of drinking water;

5. Indicator of structural and technological equipment protection (pipelines, pumping units, etc.) from fouling with zebra mussel;

6. Showing the channel-forming processes influence on a water body on the functional operation of the urban water management system associated with the sustainable selection of estimated water consumption in the water supply system of the municipal economy or industrial objects of the economy.

In the influence zones of water intakes established by the studies, quantitative and qualitative criterion indicators of the water source are determined, on the basis of which the protection level of a natural water body and municipal economy from negative factors arising from the estimated water consumption selection into the water supply system of the municipal economy is assessed. In terms of ecological significance, criterion indicators, as established by the studies [17], are determined by a certain hierarchy and are quantitatively expressed as a percentage of the standard value of the level of protection of objects of protection when using water resources in urban water systems and economic objects.

An ecological and economic assessment of the developed protective constructive and technological devices' efficiency has been carried out (STS-1, STS-2, STS-3), as an important factor in ensuring environmental safety in the zones of influence of "Urban water management complexes" where environmental safety is a property NTS "Natural water environment - Urban water management complex - Urban water supply system" to ensure the protection of the urban water management system from negative factors: associated with the ingress of ichthyofauna (fish species, etc.), entrained bottom and suspended sediments, floating objects, sludge and freeze-up during the selection of calculated water discharge from a water body to a water intake; from toxic blue-green algae and the phenomenon of fouling of technological equipment with zebra mussel.

Based on the comprehensive studies' results of the existing water intakes of urban water management systems, the basic criterion environmental indicators of environmental safety in the influence zones were determined in the following hierarchical significance:

1. The criterion indicator of the protection level for the conservation of natural biodiversity of ichthyofauna and flora (juvenile fish and aquatic vegetation) in the natural aquatic environment, which should be at least $75-85 \%$; 
2. The criterion indicator of the protection level of the water intake bucket area from sludge and floating objects coming from the water body should be at least 95$98 \%$;

3. The criterion indicator of the level of protection of the water area of the water intake bucket from bottom and suspended sediments coming from the water body should be quantitatively $90-95$;

4. The criterion indicator for the municipal water supply system protection from blue-green algae according to the requirements SanPIN must be at least 95-97\%;

5. The criterion indicator for the structural and technological equipment protection as part of the urban water management system from zebra mussel, which should be $100 \%$;

6. The criterion indicator of the water intake impact on the channel-forming processes in the zone of influence of the water intake, which is determined qualitatively on physical models on a scale of at least 1:100.

It should be noted that each criterion indicator is determined quantitatively or qualitatively by individual research for each indicator associated with the development of new or improvement of existing design solutions with the conduct of special geological, geochemical studies of aquatic ichthyofauna and vegetation. [12].

As part of an open nonequilibrium NTS «NWE-UWMC - UWSC» the technogenic component of the urban water management system water intake the is considered, respectively, as an open non-equilibrium subsystem, in which its constituent functional structural and technological elements are systematically interconnected from the intake structure directly interacting with the natural aquatic environment to the front chamber of pumping stations (Fig. 1).

Water intake of the urban water management system, as a subsystem in the composition NTS «NWE-UWMC - UWSC» functional purpose consists of three interconnected constructive and technological solutions (STS-1, STS-2, STS-3), in which the protective measures are taken to select the estimated water flow rates from a water body, protect the sampled water from various types of ichthyofauna, bottom, suspended sediments and floating objects, toxic blue-green algae and protect technological equipment from fouling with zebra mussel. Based on the analysis results, a model of the water intakes environmental safety system as a part of the urban water management system was developed (Fig. 2), in which each structural and technological scheme ensures the protection objects (PO), where PO acts as a natural aquatic environment of a water body, a water intake ladle, technological equipment for a water intake and an urban water management system. Ensuring the environmental safety of municipal services as part of NTS «NWE-UWMC - UWSC» carried out by the appointed PO, sources of environmental hazards (SEH) and protective measures $(\mathrm{PM})$, which interaction is considered in the system «PO - SEH - PM» (Fig. 2) [16].

Based on the results of process studies IIR «NWE» with the main technogenic component «UWMC» as part of the NTS «NWE-UWMC - UWSC» we can conclude that system analysis, as a method of organization and management analysis, and a system approach, as a way to create a generalized constructive and technological model, which includes STS-1, STS-2, STS-3 and ensuring the normative level of environmental safety. In the model under ES the ability of objects to be protected (PO) is understood under the influence of interaction processes «UWMC» with «NWE» on the estimated water consumption selection, as a result of which quantitative and qualitative environmental indicators of the human health and quality of life protection 
level are formed by preserving the natural biodiversity of ichthyofauna (juvenile fish, etc.), protecting the sampled water from toxic blue-green algae, fouling processes of technological equipment draining and negative factors that reduce the functional efficiency of urban water management systems.

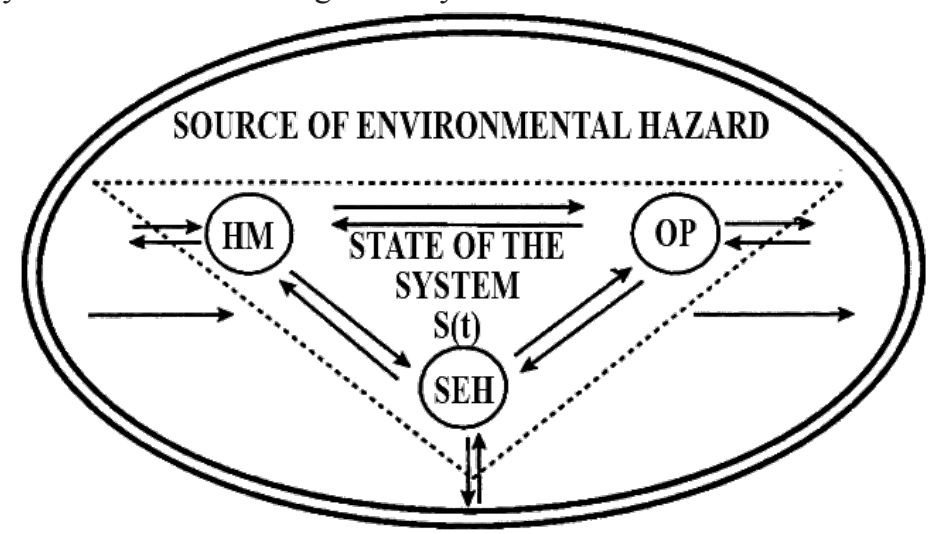

Fig. 2. Model of interaction of system components «PO - SEH - PM»

The concept of water resources rational use provides an ecosystem approach while ensuring environmental safety in the zones of urban water management systems water intakes influence, in connection with which a constructive and technological decision was made (STS-1) on the preservation of natural biodiversity (fish species and other ichthyofauna) in a water body during the development of a protective device for a water intake. The protective device is a multifunctional, environmentally acceptable soft floating structure that provides a level of protection of the water taken from the water intake (bucket) from slush, freeze-up, entrained bottom and suspended sediments and floating objects, which is made of high-strength synthetic fabric materials (Fig. 3).

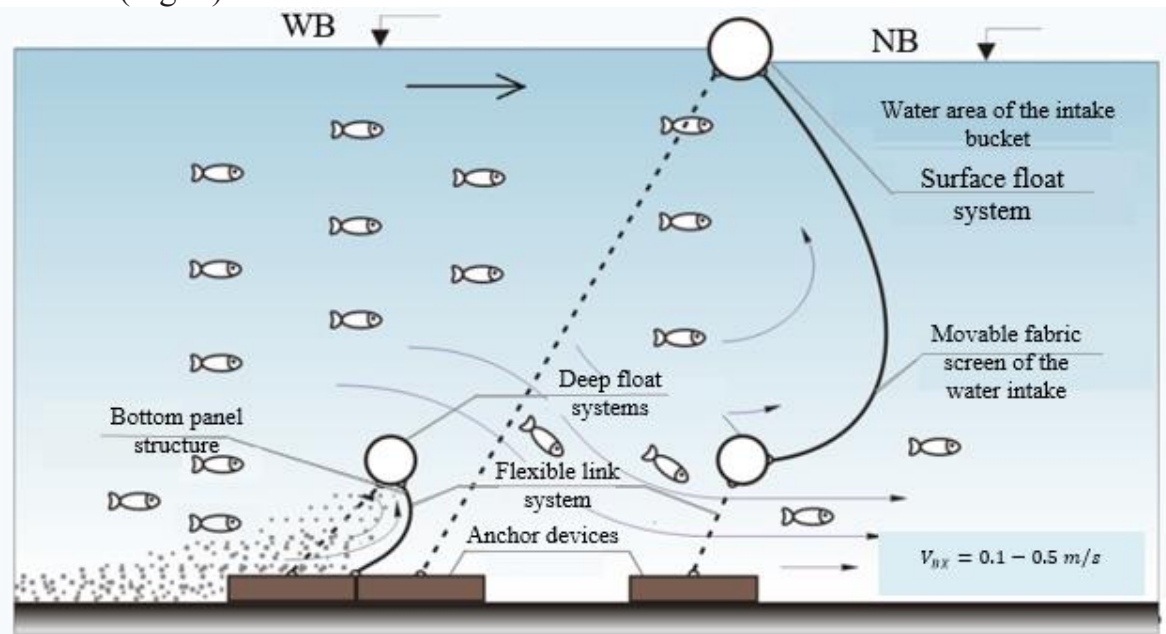

Fig. 4. Soft floating structure of the water intake structure as part of STS-1 "Urban water management complex"

In accordance with the criterion environmental indicators (4) in the second constructive and technological solutions (STS-2) protection against toxic blue-green 
algae is provided by a certain placement of the soft ruffs structure in the water area of the water intake bucket (Fig. 4), the functional efficiency (70\%) of which was determined by the laboratory studies and production tests at the water intake of water systems of the cities of Rostov-on-Don, Aksai and Bataysk.

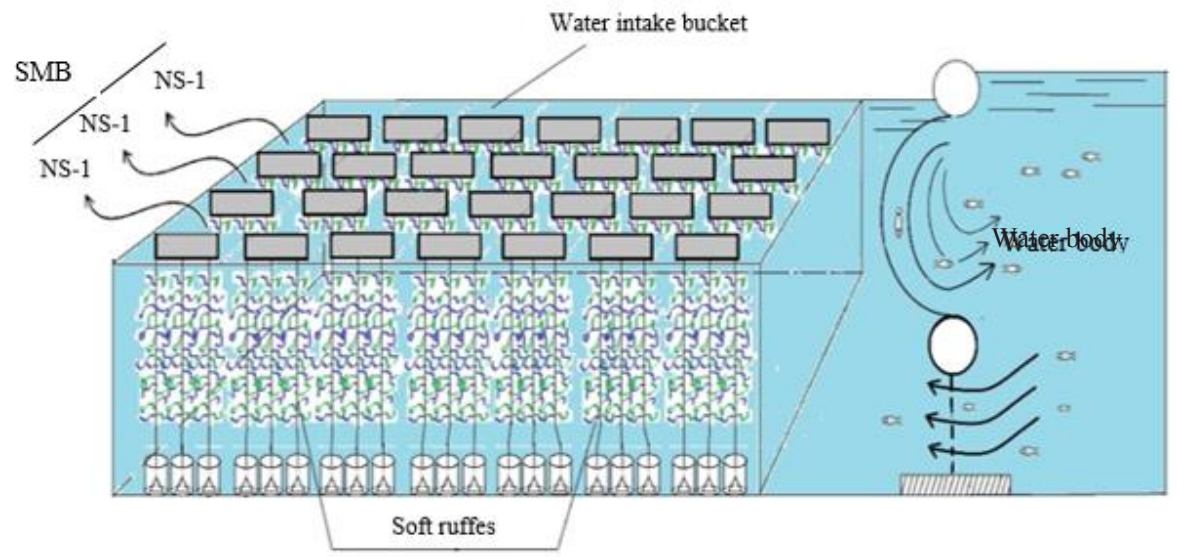

Fig.4. Design and technological solution 1

In accordance with the criterion environmental indicators (5) in the third constructive and technological solutions (STS-3) protection of the water intake equipment and pipelines of the urban water management system from the phenomenon of fouling by zebra mussel is provided by using the installation developed on the principle of plankton electro cupping (Fig. 5), which is installed at the inlet of the water intake heads of pumping stations (Fig. 6).

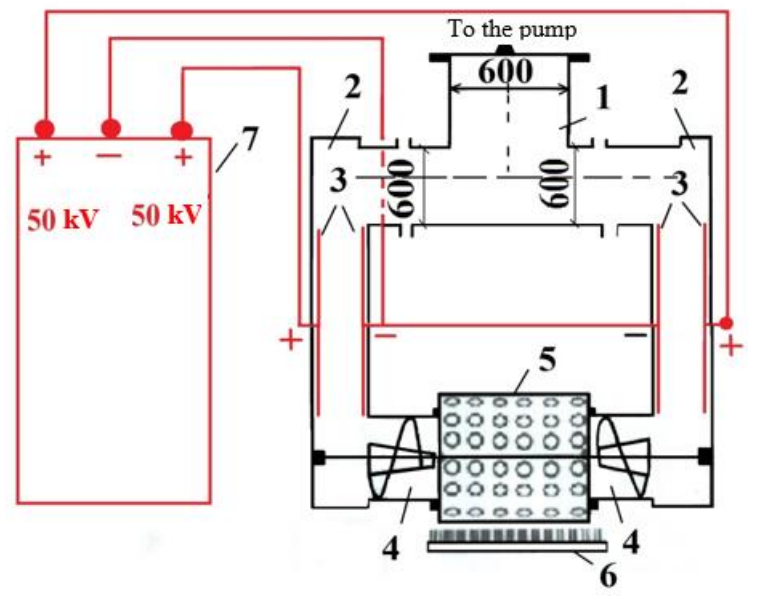

Fig. 4. Design and technological solution 2: 1-suction pipe; 2-chamber for plankton electro cupping; 3-electrodes; 4-hydraulic turbine; 5-rotating trash-holding grid; 6brush for cleaning the rotating mesh; 7-pulse current generator 


\section{Conclusion}

Based on the results of system analysis as a method for process control, interconnections, interactions and relationships between the constructive and technological solutions (STS-1, STS-2, STS-3) as a part of the main technogenic component - the intake structure of the urban water management system as part of a specialized type NTS «NWE-UWMC - UWSC» and a systematic approach, as a way to create a multi-stage constructive and technological solution to ensure the normative level of environmental safety in the processes of using water resources, three constructive and technological devices have been developed - STS-1, STS-2, STS-3, in which a new type of water intake structure is applied, for the first time, soft ruffs for drinking water purification and protective devices based on the principle of electro cupping, which ensure regulatory environmental safety in the zones of urban water management ' water intake influence.

The ecological safety of water intakes in urban water systems and the creation of comfortable conditions for the life of the population can be ensured only with a comprehensive solution of problems related to improving the safety of quality indicators of water when it is taken from the source, preserving biodiversity in a water body, protection from blue-green algae, zebra mussel and mechanical pollution.

\section{References}

1. V.L. Bondarenko, A.I. Ylyasov, E.D. Khetsuriani, monograph Scientific and methodological foundations of natural-technical systems in the use of water resources: territories of basin geosystems (Novocherkassk, 2019)

2. V.L. Bondarenko, E.A. Semenova, A.V. Aliferov, O.V, Klimenko, Natural and technical systems in the use of water resources: territories of basin geosystems: monograph (NPI, Novocherkassk, 2016)

3. V.L. Bondarenko, V.B. Dyachenko, Problems of regional ecology 2, 86-92 (2005)

4. M.I. Budyko, O.A. Drozdov, About moisture turnover in a limited land area. Questions of hydrometeorological efficiency of field protection afforestation (Gidrometeoizdat, L., 1950)

5. V.A. Volosukhin, V.L. Bondarenko, Building systems for the protection of water resources using the structures from fabric materials: monograph (Colorit, Novocherkassk, 2008)

6. K.S. Losev, Environmental problems and prospects for sustainable development of Russia in the XXI century (Kosmosinform, M., 2001)

7. A.M. Chernyaeva, River basins (Publishing house Agroecology, Yekaterinburg, 1999)

8. E.D. Khetsuriani, V.P. Kostyukov, E.G. Ugrovatova, Hydrological research on the river Don in Aleksandrovsky WWS Water intake facilities. Procedia techniques 150 (2nd International Conference on Industrial Engineering, ICIE 2016) May 19 2016, Chelyabinsk, Russia (2016)

9. E.D. Khetsuriani, T.E. Khetsuriani, measures will be taken to combat the eutrophication of water bodies priority tasks and strategies for the development of 
agricultural science: Sat. science tr (international Scientific practical Conference FTSNiO EVENSIS) May 25, 2016, Tolyatti, Russia (2016)

10. E.D. Khetsuriani, L.N. Fesenko, A.N. Bogachev, M.M. Mordvinuev, G.N. Puras, A. Yu. Dushenko, R.S. Bechvaya, A.V. Pelcher, Engineering Journal of Don 4 (2015)

11. E.D. Khetsuriani, V.P. Kostyukov, T.E. Khetsuriani, IOP Conference Series: Materials Science and Engineering 262 (2017)

12. E.D. Khetsuriani, V.L. Bondarenko, N.A. Polyansky, IOP Conference Series: Materials Science and Engineering 262 (2018)

13. E.D. Khetsuriani, V.L. Bondarenko, A.I. Ylyasov, E.A. Semenova, The results of the research on the pipelines protection from Zebra mussle on the water intake technological complexes of multi-purpose water supply systems for urban farms, IOP Conference Series: Materials Science and Engineering 698, 055041 (2019). International Scientific Conference "Construction and Architecture: Theory and Practice of Innovative Development" 1-5 October 2019, Kislovodsk, Russia https://iopscience.iop.org/article/10.1088/1757-899X/698/5/055041/pdf

14. E.D. Khetsuriani, V.L. Bondarenko, A.I. Ylyasov, E.A. Semenova, Lightweight constructions in technical water supply systems of thermal and nuclear power plants, IOP Conference Series: Materials Science and Engineering 698, 055042 (2019). International Scientific Conference "Construction and Architecture: Theory and Practice of Innovative Development" 1-5 October 2019, Kislovodsk, Russia. https://iopscience.iop.org/article/10.1088/1757-899X/698/5/055042/pdf

15. E.D. Khetsuriani, V.L. Bondarenko, A.I. Ylyasov, E.A. Semenova, Innovative design solutions to ensure the environmental safety in the existing water intake technological complexes of water systems for urban farms, IOP Conference Series: Materials Science and Engineering 698, 055040 (2019). International Scientific Conference "Construction and Architecture: Theory and Practice of Innovative Development" 1-5 October 2019, Kislovodsk, Russia. https://iopscience.iop.org/article/10.1088/1757-899X/698/5/055040/pdf

16. E.D. Khetsuriani, V.L. Bondarenko, A.I. Ylyasov, E.A. Semenova, Development of protective measures providing environmental safety in areas affected by waterintake constructions of urban households, IOP Conference Series: Materials Science and Engineering 698, 077053 (2019). International Scientific Conference "Construction and Architecture: Theory and Practice of Innovative Development" 1-5 October 2019, Kislovodsk, Russia https://iopscience.iop.org/article/10.1088/1757-899X/698/7/077053/pdf

17. E.D. Khetsuriani, V.L. Bondarenko, A.I. Ylyasov, Scientific and methodological foundations of environmental safety at water intake technological complexes of multipurpose water supply systems: monograph (Platov South-Russian State Polytechnic University (NPI), Novocherkassk, 2020) 